Arq. Bras. Med. Vet. Zootec., v.70, n.3, p.793-796, 2018

\title{
Hemangioma esclerosante mandibular em Paralichthys orbignyanus: relato de caso
}

\author{
[Sclerosing hemangioma mandibular in Paralichthys orbignyanus: case report]
}

\author{
M.C. Klosterhoff, L.A. Sampaio, M.H. Okamoto, V.F. Pedrosa, L.A. Romano
}

Universidade Federal do Rio Grande - Rio Grande, RS

\begin{abstract}
RESUMO
Neste trabalho, descreveu-se o primeiro caso de hemangioma esclerosante registrado em um exemplar adulto do linguado Paralichthys orbignyanus. Produzido a partir de reprodução artificial, o peixe em questão tinha aproximadamente 10 anos de idade e fazia parte de um plantel de reprodutores. Ao ser retirado do tanque, notou-se a presença de lesão mandibular com escoriações e focos hemorrágicos. Amostras do tumor foram coletadas da mandíbula para análise histopatológica. Microscopicamente foi observada uma proliferação de numerosos vasos sanguíneos rodeados por um estroma conectivo denso. A etiologia dessa neoplasia é desconhecida, mas o fato de o exemplar ter permanecido por muitos anos em cativeiro pode ter contribuído para o surgimento desse tipo de lesão, devido aos choques mecânicos contra a parede do tanque que acontecem esporadicamente.
\end{abstract}

Palavras-chave: histopatológica, mandíbula, neoplasia

\begin{abstract}
In this study, we described the first case of sclerosing haemangioma in an adult Brazilian flounder Paralichthys orbignyanus. Produced by artificial reproduction, the fish was approximately 10 years old and was maintained at a breeding stock. When removed from the tank, mandibular lesion with excoriations and hemorrhagic foci were noted. Tumor samples were collected from the mandible for histopathological analysis. Proliferation of numerous blood vessels surrounded by dense connective stroma was observed microscopically. The etiology of this neoplasia is unknown, but the fact that the specimen remained in captivity for many years, may have contributed to the appearance of this type of lesion, due to sporadic mechanical shocks to the tank wall.
\end{abstract}

Keywords. histopathological, mandible, neoplasia

\section{INTRODUÇÃO}

Em peixes, assim como em outros vertebrados, pode acontecer o desenvolvimento de neoplasias em quase todos os seus tecidos. A histogênese dessa neoplasia é semelhante à que ocorre em mamíferos e humanos, o que faz desses animais um interessante modelo para se realizarem interpretações filogenéticas de neoplasias. Existem vários casos de neoplasias em peixes, todas elas com grande similaridade às relatadas em humanos (Romano e Marozzi, 2004; Romano et al., 2015).
Os hemangiomas são neoplasias frequentes em mamíferos e humanos, no entanto este tipo esclerosante de hemangioma em humanos é um tumor pouco frequente, descrito pela primeira vez por Liebow e Hubbell (1956), tendo, neste caso específico, afetado o pulmão.

Não há muitas revisões sobre neoplasias em peixes. Uma das referências mais citadas é a de Mawdesley-Thomas (1975), que relata 407 neoplasias em várias espécies de peixes, entre essas só um caso de hemangioma, reportado por Johnstone (1925), em Pleuronectes platessa. Entretanto, a primeira publicação sobre

Recebido em 30 de novembro de 2016

Aceito em 10 de outubro de 2017

E-mail: mcklosterhoff@gmail.com 
hemangiomas em peixes foi de Drew (1912), que publicou dois casos desses tumores em Raia maculata e em Trigla lineata.

Todos esses hemangiomas se localizavam em tecidos moles, podendo ocorrer em tecido cartilaginoso, tecido adiposo, vasos sanguíneos, tecido conjuntivo e tecido muscular liso e estriado, com aparência histológica variável (Rosai, 2004). Em uma revisão anterior sobre neoplasia em peixes descrita por MawdesleyThomas (1975), relatam-se casos de hemangioma em vísceras, como o fígado.

Neste artigo, reportou-se um caso de hemangioma esclerosante, localizado na mandíbula de uma exemplar fêmea de Paralichthys orbignyanus adulta, criada em um sistema de recirculação de água (SRA).

\section{CASUÍSTICA}

Uma fêmea de $P$. orbignyanus, de 10 anos de idade, com comprimento de $62 \mathrm{~cm}$, peso de $3,8 \mathrm{~kg}$ e fator de condição $\mathrm{K}: 1,6$, criada em SRA da Estação Marinha de Aquacultura do Instituto de Oceanografia da Furg (Universidade Federal do Rio Grande), apresentou uma lesão de aspecto congestivo, de superfície irregular e consistência rígida, com dimensões de $8 \times 4 \mathrm{~cm}$, localizada na região maxilar ventrolateral. Essa lesão apresentava escoriações e focos hemorrágicos, secundárias a traumatismos por choques com as paredes e o fundo do tanque (Fig. 1). O peixe foi eutanasiado com uma dose letal de cloridrato de benzocaína $(300 \mathrm{mg} / \mathrm{L})$. Posteriormente, foi realizada a necropsia, prática em conformidade com o Conselho Nacional de Controle da Experimentação Animal (Concea) e aprovada pela Comissão de Ética em Uso Animal da Universidade Federal do Rio Grande (CeuaFurg), $n^{\circ}$ P047/2016. O exame histopatológico da lesão demonstrou uma proliferação de estruturas vasculares irregulares, repletas de eritrócitos, circundadas por tecido conectivo, em sua maioria, denso, com algumas áreas de aspecto mixoide com células estromais vacuoladas. Em cortes histológicos, foram observados eritrócitos extravasados, formando focos de hemorragia. Por meio da coloração de tricrômico de Masson, foi evidenciado o acúmulo de tecido fibroso circundando as estruturas vasculares (Fig. 2, 3 e 4).

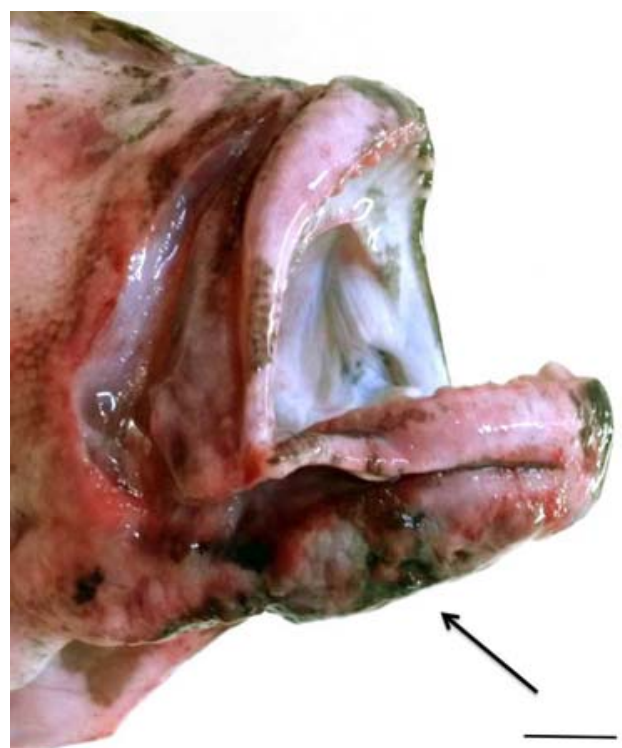

Figura 1. Exame macroscópico; lesão de aspecto congestivo, localizada na região maxilar ventrolateral (seta), Bar: $3 \mathrm{~cm}$.

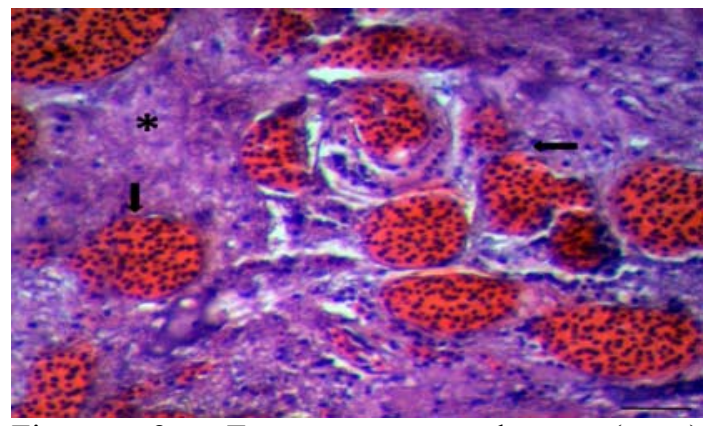

Figura 2. Estruturas vasculares (setas) circundadas por tecido conectivo fibroso $(*)$, em sua maioria denso, com algumas áreas de aspecto mixoide com células estromais vacuoladas. HE, Bar: $20 \mu \mathrm{m}$.

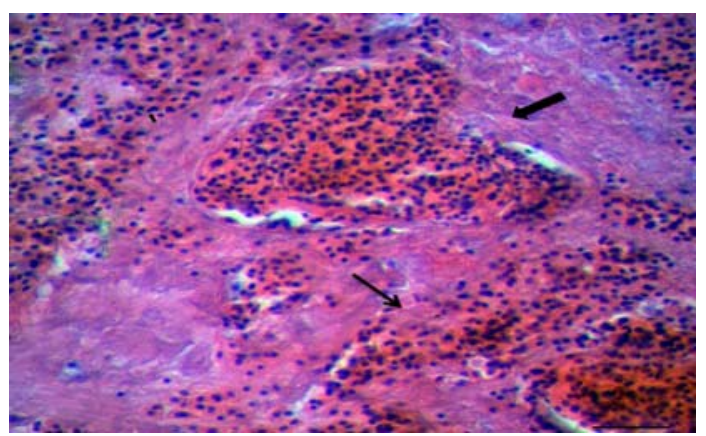

Figura 3. Exame microscópico; proliferação de estruturas vasculares irregulares (seta grossa), com eritrócitos extravasados (seta fina), formando focos de hemorragia. HE Bar: $20 \mu \mathrm{m}$. 


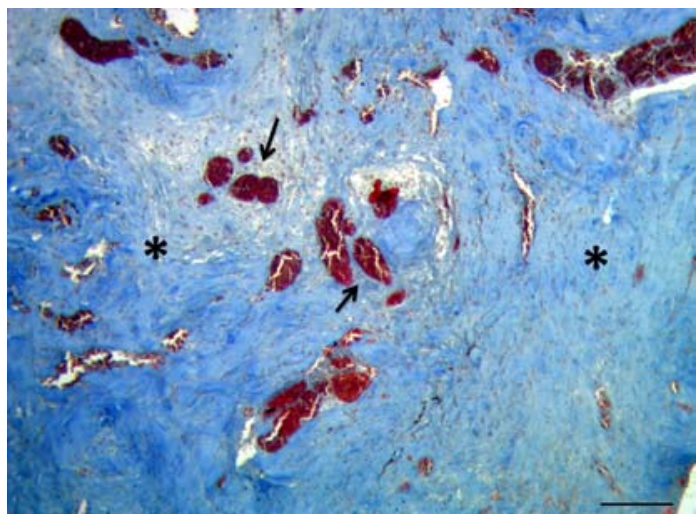

Figura 4. Acúmulo de tecido fibroso (*) circundando as estruturas vasculares (setas). Tricrômico de Masson, Bar: $200 \mu \mathrm{m}$.

\section{DISCUSSÃO}

Os peixes apresentam tumores semelhantes aos reportados em mamíferos, incluindo humanos, pela similaridade de sua histogênese e classificação (Mawdesley-Thomas, 1975). Os hemangiomas consistem em neoplasias vasculares que crescem por uma rápida proliferação celular a partir de células endoteliais. Possuem, como característica, uma fase proliferativa inicial, seguida de uma fase involutiva, em que a proliferação endotelial diminui e surge tecido fibroso separando os espaços vasculares (Rosai, 2004).

A classificação mais aceita até o momento, desde sua descrição em 1982, é a de Mulliken e Glowacki (1982), a qual permite diferenciar os hemangiomas e as malformações vasculares, que apresentam um comportamento evolutivo diferente.

O hemangioma esclerosante tem recebido diversas denominações, tais como angioma esclerosante ou pseudotumor xantomatoso, descrito inicialmente como um tumor vascular, com infiltração celular, zonas de esclerose e hemorragia. A origem histológica dessa lesão tem sido amplamente discutida, sendo atribuída a uma origem mesenquimática; esses hemangiomas são incluídos nos tumores de tecidos moles (Rosai, 2004).

O mecanismo exato por meio do qual se origina o hemangioma permanece desconhecido, sendo descritos fatores de crescimento tissular com papel em sua etiogênese. Estudos imuno- histoquímicos documentaram um aumento na expressão do fator de crescimento fibroblástico e do fator de crescimento vascular endotelial, no antígeno celular de proliferação nuclear e na colagenase tipo IV (North et al., 2000; Hering et al., 2006).

O fator de condição do animal em estudo foi $\mathrm{K}=1,6$, considerado um valor de boa condição de saúde, prova de que o animal estaria se alimentando normalmente, não se atribuindo o fato de a lesão na mandíbula estar impedindo sua alimentação. Para essa espécie, um fator de condição negativo é considerado abaixo de 1 . Robaldo et al. (2012) reportaram um maior fator de condição em linguados criados em cativeiro $(\mathrm{K}=1,3)$, comparado com linguados selvagens $(\mathrm{K}=1,1)$, sendo essa tendência atribuída à condição de sedentarismo dos animais dentro de tanques indoor.

No caso aqui apresentado, existem dois fatores que podem predispor à presença de neoplasias desse tipo: o envelhecimento: alguns autores sustentam a teoria de que os peixes mantidos em cativeiro durante anos desenvolvem neoplasias mais frequentemente (Stoskopf, 1993) e fatores mecânicos: outros autores afirmam que o contínuo contato com as paredes e o fundo dos tanques, onde os peixes são criados, pode gerar neoplasias cutâneas ou de tecidos moles subcutâneos (Britos e Balone, 2013).

\section{CONCLUSÕES}

Neste artigo, reportou-se um caso de hemangioma esclerosante na mandíbula de uma fêmea de Paralichthys orbignyanus, criada em um sistema de recirculação. A etiologia dessa neoplasia permanece desconhecida, mas o fato de esse animal ter permanecido por muito tempo em um sistema de criação pode ter contribuído para o surgimento desse tipo de neoplasia. Além disso, esporadicamente acontecem choques contra as paredes dos tanques, representando um fator mecânico, que, caso se mantenha ao longo do tempo, pode vir a provocar lesão neoplásica.

\section{AGRADECIMENTOS}

Os autores agradecem à Capes (Coordenação de Aperfeiçoamento de Pessoal de Nível Superior), pelo apoio financeiro. L.A. Romano é pesquisador do CNPq brasileiro (301245/2016-9). 


\section{REFERÊNCIAS}

BRITOS, J.L.; BALONE, L. Factores físicos que pueden generar neoplasias en vertebrados inferiores. Rev. Soc. Cient. Arg., v.64, p.20-25, 2013.

DREW, G.H. Some cases of new growths in fish. J. Mar. Biol. Assoc., v.9, p.281-287, 1912.

HERING, S.; SARMIENTO, F.G.R.; VALLE, L.E. Actualizacion en el diagnóstico y tratamiento de los hemangiomas. Rev. Argent. Dermatol., v.87, p.54-66, 2006.

JOHNSTONE, J. Malignant tumours in fishes. Liverpool Biol. Soc. Proc. Tans., v.39, p.169200, 1925.

LIEBOW, A.A.; HUBBELL, D.S. Sclerosing hemangioma (his- tiocytoma, xanthoma) of the lung. Cancer, v.9, p.53-75. 1956.

MAWDESLEY-THOMAS, L.E. Neoplasia in fish. In: RIBELIN, L.W.E.; MIGAKI, G. (Eds.). The pathology of fishes. Wisconsin: University of Wisconsin Press, 1975. p.805-870.

MULLIKEN, J.B.; GLOWACKI, J. Hemangiomas and vascular malformations in infants and children: a classification based on endothelial characteristics. Plast Reconstr. Surg., v.69, p.412, 1982.
NORTH, P.E; WANER, M.; MIZERACKI, A. et al. GLUT1: a newly discovered immunohistochemical marker for juvenile hemangiomas. Hum. Pathol., v.31, p.11-22, 2000.

ROBALDO, B.; RODRIGUES, R.V.; OKAMOTO, M.H. et al. Processing yield of wild-caught and indoor-reared Brazilian flounder Paralichthys orbignyanus. J. Appl. Ichthyol. 1-3, 2012.

ROMANO, L.A.; KLOSTERHOFF, M.; FUHR, F. et al. Multiple neurofibromas of the heart in wild carp, Cyprinus carpio: optical, imunohistochemical and ultrastructural study. Bull. Eur. Assoc. Fish Pathol., v.34, p.201-207, 2015.

ROMANO, L.A.; MAROZZI, A.V. Epithelioreticular cell thymoma in carp Cyprinus carpio L: a case with ultrastructural study. J. Fish Dis. v.27, p.369-373, 2004.

ROSAI, J. Soft tissues. In: Rosai and Ackerman's surgical pathology. London: Mosby, 2004. p.2237-2373.

STOSKOPF, M.K. Golfish, koi, and carp neoplasia. In: STOSKOPF, M.K. (Ed.). Fish medicine. London: Saunders Press, 1993. p.490491. 